
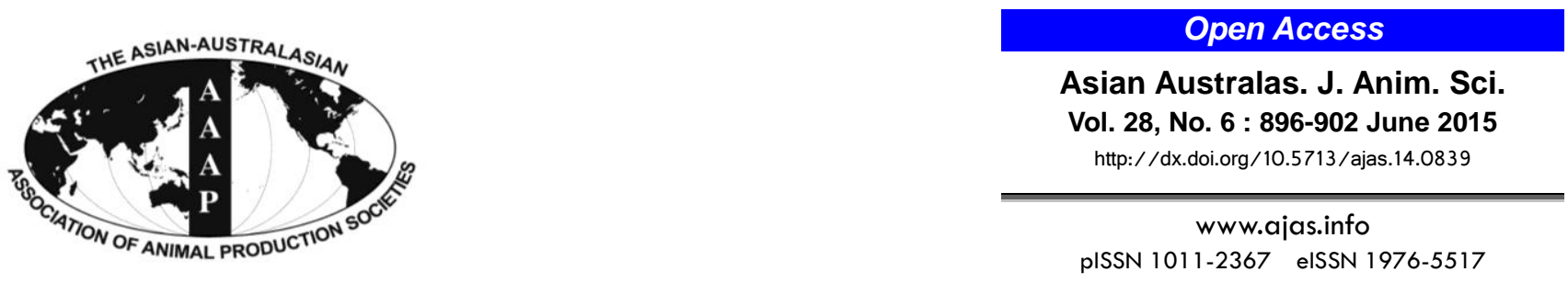

\title{
Nitrogen Removal from Milking Center Wastewater via Simultaneous Nitrification and Denitrification Using a Biofilm Filtration Reactor
}

\author{
Seung-Gun Won, Dae-Yong Jeon, Jung-Hoon Kwag ${ }^{1}$, Jeong-Dae Kim, and Chang-Six Ra* \\ Department of Animal Life System, Kangwon National University, Chuncheon 200-701, Korea
}

\begin{abstract}
Milking center wastewater (MCW) has a relatively low ratio of carbon to nitrogen (C/N ratio), which should be separately managed from livestock manure due to the negative impacts of manure nutrients and harmful effects on down-stream in the livestock manure process with respect to the microbial growth. Simultaneous nitrification and denitrification (SND) is linked to inhibition of the second nitrification and reduces around $40 \%$ of the carbonaceous energy available for denitrification. Thus, this study was conducted to find the optimal operational conditions for the treatment of $\mathrm{MCW}$ using an attached-growth biofilm reactor; i.e., nitrogen loading rate (NLR) of $0.14,0.28,0.43$, and $0.58 \mathrm{~kg} \mathrm{~m}^{-3} \mathrm{~d}^{-1}$ and aeration rate of $0.06,0.12$, and $0.24 \mathrm{~m}^{3} \mathrm{~h}^{-1}$ were evaluated and the comparison of air-diffuser position between one-third and bottom of the reactor was conducted. Four sand packed-bed reactors with the effective volume of $2.5 \mathrm{~L}$ were prepared and initially an air-diffuser was placed at one third from the bottom of the reactor. After the adaptation period of 2 weeks, SND was observed at all four reactors and the optimal NLR of $0.45 \mathrm{~kg} \mathrm{~m}^{-3} \mathrm{~d}^{-1}$ was found as a threshold value to obtain higher nitrogen removal efficiency. Dissolved oxygen (DO) as one of key operational conditions was measured during the experiment and the reactor with an aeration rate of $0.12 \mathrm{~m}^{3} \mathrm{~h}^{-1}$ showed the best performance of $\mathrm{NH}_{4}-\mathrm{N}$ removal and the higher total nitrogen removal efficiency through SND with appropriate DO level of $\sim 0.5 \mathrm{mg} \mathrm{DO} \mathrm{L}{ }^{-1}$. The air-diffuser position at one third from the bottom of the reactor resulted in better nitrogen removal than at the bottom position. Consequently, nitrogen in MCW with a low $\mathrm{C} / \mathrm{N}$ ratio of 2.15 was successfully removed without the addition of external carbon sources. (Key Words: Carbon to Nitrogen Ratio, Milking Center Wastewater, Nitrogen Loading Rate, Simultaneous Nitrification and Denitrification)
\end{abstract}

\section{INTRODUCTION}

Extensive livestock management has successfully increased the quantity of meat and dairy products. At the same time, the excretion of livestock manure remarkably increases and threats clean surface water when discharged without appropriate treatments. Animal wastewater has much higher concentrations of carbon, nitrogen, and phosphorus when compared to municipal wastewater. Among the livestock categories, milking center wastewater (MCW) from dairy farm occurs from washing tanks,

\footnotetext{
* Corresponding Author: Chang-Six Ra. Tel: +82-33-250-8618, Fax: +82-33-251-7719, E-mail: changsix@kangwon.ac.kr

${ }^{1}$ National Institute of Animal Sciences, RDA, Suwon, 441-350, Korea.
}

Submitted Oct. 24, 2014; Revised Dec. 31, 2014; Accepted Jan. 12, 2015 pipelines, equipment, holding area floor, and facilities, and during preparing cows for milking, so the wastewater inevitably contains milk, detergents, disinfectant as well as manure. The quantity of wastewater varies depending on the types of milking facilities and the size of herds (Safferman, 2008). Milking parlor wastewater is recommended to store separately from livestock manure due to negative impacts on manure nutrients and harmful effects on down-stream of livestock manure process with respect to the microbial growth. First of all, this specific wastewater contains the low carbon to nitrogen $(\mathrm{C} / \mathrm{N})$ ratio in terms of nitrogen removal and various non-degradable compounds such as detergents, disinfectant, and milk as a major nitrogen source. Thus, it is important to develop an effective treatment system for MCW.

In the biological process, nitrogen removal is achieved

Copyright (? 2015 by Asian-Australasian Journal of Animal Sciences This is an open-access article distributed under the terms of the Creative Commons Attribution Non-Commercial License (http://creativecommons.org/licenses/by-nc/3.0/), which permits unrestricted non-commercial use, distribution, and reproduction in any medium, provided the original work is properly cited. 
through nitrification by autotrophs and denitrification by heterotrophs; i.e., nitrification occurs under aerobic condition in which ammonium- $\mathrm{N}$ is oxidized firstly to nitrite, then to nitrate. Denitrification reaction in which carbon sources are required occurs under anoxic condition. Biological nitrogen removal has been well established using two-stage conventionally as well as sequencing batch reactor in a single-vessel (Tchobanoglous et al., 2003).

However, simultaneous nitrification and denitrification (SND) has recently been found at various types of process units with advantages over the conventional processes like two-step process (aerobic/anoxic phases) such as the cost saving for anoxic tank and the addition of external carbon sources during the denitrification (Münch et al., 1996). Irvine et al. (1987) found $80 \%$ of inorganic nitrogen was disappeared in their full-scale sequencing batch reactor. Moriyama et al. (1990) observed denitrification with dissolved oxygen (DO) concentration of 0.2 to $0.5 \mathrm{mg} \mathrm{L}^{-1}$ at oxic condition called "aerobic denitrification". Organic carbon could be theoretically saved up to $40 \%$ through SND since the lower amount of carbon sources is required for nitrite reduction $(2.80 \mathrm{mg}$ carbon sources as chemical oxygen demand (COD); $4.95 \mathrm{mg}$ COD for nitrate reduction) (Turk and Mavinic, 1986; Seyfried et al., 2001). Thus, the SND reaction might be particularly appropriate to treat the wastewater contained a low $\mathrm{C} / \mathrm{N}$ ratio. Turk and Mavinic (1986; 1989) has reported that higher denitrification rates and a lower biomass yield were achieved during aerobic growth. Activated sludge flocs could have aerobic (outer) and anoxic (inner) zone according to DO gradient along with the layers of flocs. Other than suspended growth system, fixed bed reactors and biological contactor units had also been reported about SND (Masuda et al., 1991; Halling and Hjuler, 1992; Gupta et al., 1994; Sen and Dentel, 1998). One of key parameters for SND would be the concentration of DO. Oxygen diffuses into the layers of microbial flocs for suspended growth or biofilm for attached growth and is consumed by nitrifiers. Gradually, oxygen concentration decreased and the inner zone of the flocs becomes anoxic condition since nitrite and nitrate play a role as an electron acceptor (Zeng et al., 2003).

Hence, the present study aims to achieve the nitrogen removal from $\mathrm{MCW}$ which contains a low $\mathrm{C} / \mathrm{N}$ ratio via SND without external carbon sources for denitrification using a biofilm filtration system which was optimized with respect to i) nitrogen loading rate (NLR), ii) an appropriate position of air-diffuser, and iii) an aeration rate for SND.

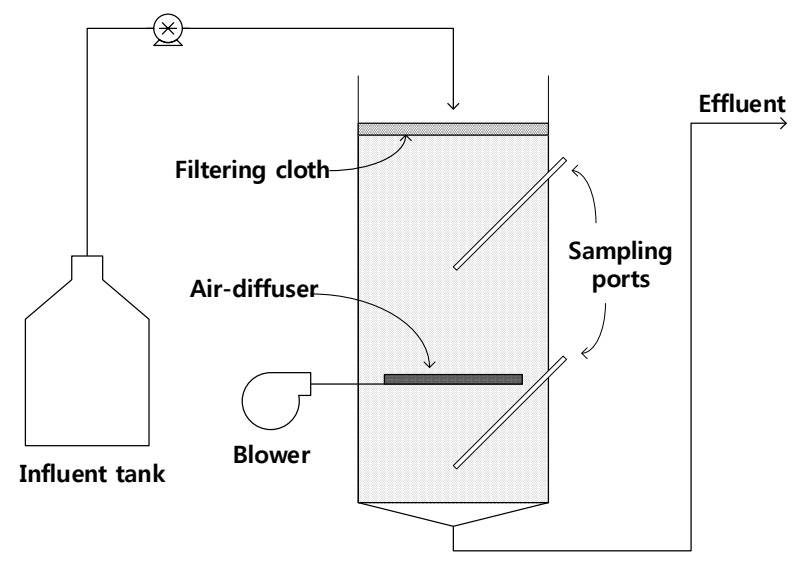

Figure 1. Schematic layout of biofilm filtration system per set.

\section{MATERIALS AND METHODS}

\section{System configuration and process operation}

Four sets of biofilm reactor were prepared with total volume of $8 \mathrm{~L}$ including bedding materials in each. The sand with average $2.5 \mathrm{~mm}$ diameter was packed in the reactor as a bedding material, which resulted in the effective volume of $2.5 \mathrm{~L}$ (the void fraction $\sim 0.31$ ) and provided approximately $13.2 \mathrm{~m}^{2}$ of surface area for attached microbial growth. The influent was firstly filtered with cloth which was widely used on the farm and then introduced to the top of the bedding material in which the cloth covered in 3 layers. Thus, most coarse solids and gooey contents in MCW were taken out. The air-diffuser was placed on one-third of the reactor from the bottom and air was supplied continuously with an aeration rate of 0.12 $\mathrm{m}^{3} \mathrm{~h}^{-1}$, whereby the aerobic and anoxic phases were formed at upper and lower zone, respectively. The effluent was discharged from the bottom of the reactor without pumps by the elongated line to the surface level of the reactor, namely the effluent was naturally discharged via the outlet by atmospheric pressure. The reactor also had 2 sampling ports on the side for sampling from both different zones (aerobic and anoxic zones) (Figure 1).

At the beginning of the experiment, return activated sludge prepared from public municipal sewage treatment facilities was inoculated in the reactor, and was adapted with diluted MCW (1:10) for two months.

In order to find an optimal NLR, four biofilm reactors were operated with the different flow rate of influent which led to 4 different NLRs in each reactor for six months (Table 1). Four different flow rates were maintained by a

Table 1. Nitrogen loading rate in four reactors according to varying hydraulic retention time for 6 months

\begin{tabular}{lcccc}
\hline & $\mathrm{R} 1$ & $\mathrm{R} 2$ & $\mathrm{R} 3$ & $\mathrm{R} 4$ \\
\hline HRT (d) & $3.3-8.3$ & $1.7-4.2$ & $1.1-2.8$ & $0.8-2.1$ \\
NLR $\left(\mathrm{kg} \mathrm{T}-\mathrm{N} \mathrm{m}^{-3} \mathrm{~d}^{-1}\right)$ & $0.14 \pm 0.05$ & $0.29 \pm 0.10$ & $0.44 \pm 0.16$ & $0.58 \pm 0.21$ \\
\hline
\end{tabular}

R1-4, labelling for four reactors; HRT, hydraulic retention time; NLR, nitrogen loading rate; T-N, total nitrogen. 
peristaltic pump and the influent was continuously introduced into the reactor. In order to maintain NLR designated in $\mathrm{R} 1 \sim 4$, the influent flow rates were separately adjusted, which resulted in the wide ranges of hydraulic retention time (HRT) under the four different NLR conditions as shown in Table 1. After the optimal NLR was determined, the position of air-diffuser was compared in between the one third and bottom of the reactor. Since the air-diffuser position resulted in the formation of aerobic or anoxic zone, the performance of nitrogen removal through SND might be compared to the separated reactions of nitrification and denitrification. Thus, two biofilm reactors had the air-diffuser at one-third of the reactor and the other two reactors had the air-diffuser at the bottom of the reactor for three months. It might be expected that aerobic and anoxic zones formed separately when the air-diffuser was placed at one third of the reactor.

Finally, the aeration rates of $0.06,0.12$, and $0.24 \mathrm{~m}^{3} \mathrm{~h}^{-1}$ were also tested for two months. Thus, the performance of the biofilm reactor for nitrogen removal was evaluated with consideration of DO level.

\section{Analytical methods}

Milking center wastewater was collected from the research and development center in Seoul Dairy Co. every 2nd week throughout the experiment. All the influent and effluent were collected every 2 nd day and analyzed as quickly as possible and stored at $4{ }^{\circ} \mathrm{C}$, but the samples for comparison between upper and lower the air-diffuser were taken once a week using sampling ports. Once samples were collected, solids analysis (total solids, TS; total volatile solids, TVS; suspended solids, SS; volatile suspended solids, VSS) were firstly measured. The rest of the samples were centrifuged at 3,000 rpm for $10 \mathrm{~min}$ and the supernatant was analyzed for biochemical oxygen demand $\left(\mathrm{BOD}_{5}\right)$ and $\mathrm{COD}_{\mathrm{cr}}$ according to Standard methods (APHA, 1995).

Auto water analyzer (QuikChem 8500 series 2, LaChat, Milwaukee, WI, USA) was used for the analysis of nitrogen and phosphorus; i.e., $\mathrm{NH}_{4}-\mathrm{N}, \mathrm{NO}_{\mathrm{x}}-\mathrm{N}$, and ortho phosphate (O-P) were measured using the analyzer and total nitrogen (T-N) and total phosphate (T-P) were also analyzed after digestion with a block digester (BD 46, LaChat, USA). During the experimental period, the DO concentration was measured by DO meter (YSI 58, YSI Inc., Yellow Springs, Ohio, USA). The mean differences among the treatments were statistically analyzed and indicated according to Tukey's HSD test (p0.05) using JMP 10.0.0 (SAS Inc., Cary, NC, USA).

\section{RESULTS AND DISCUSSION}

\section{Characteristics of milking center wastewater}

The characteristics of wastewater filtered through cloth were very fluctuated during the experimental period and summarized in Table 2. The MCW had a high fraction of inert solids as calculated that the ratio of TVS to TS was only 0.5 . Further, the SS in MCW was relatively low but very variable as seen by $707.7 \pm 499.8 \mathrm{mg} \mathrm{L}^{-1}$. Besides, the volatile fraction in SS was only 0.1 , all of which solids in MCW were mostly inert solid that could not be easily biodegradable as mentioned. On the other hand, the $\mathrm{BOD}_{5}$ to $\mathrm{COD}_{\text {cr }}$ ratio of 0.8 was observed, which implied that a major fraction of dissolved organic matter contained in MCW was readily biodegradable.

The ratio of $\mathrm{BOD}_{5}$ to $\mathrm{T}-\mathrm{N}$ was around 2.1 which had too low carbon content to obtain effective biological nitrogen removal via nitrification and denitrification. The ionized inorganic nitrogen occupied $20 \%$ of T-N in MCW and $34 \%$ of T-P was soluble phosphate.

\section{Optimization of nitrogen loading rate}

Firstly, the air-diffuser was placed at one third from the bottom of the reactor and operated with the constant aeration rate of $0.12 \mathrm{~m}^{3} \mathrm{~h}^{-1}$ in all four reactors. As described in Table 1, the NLR of $0.14,0.28,0.43$, and $0.58 \mathrm{~kg} \mathrm{TN} \mathrm{m}^{-3}$ $\mathrm{d}^{-1}$ in each reactor was tested. The effluent characteristics and the removal efficiencies are tabulated in Table 2. The removal efficiencies of $\mathrm{BOD}_{5}$ showed relatively high over $85 \%$ in all the reactors, while the highest removal efficiency of $\mathrm{COD}_{\mathrm{cr}}$ was only $71 \%$ at $\mathrm{R} 1$, which was because a portion of inert organic compounds was not counted in $\mathrm{BOD}_{5}$. The Figure 2 delineates the removal efficiencies and the concentration of $\mathrm{BOD}_{5}$ in effluent with different organic loading rate. When OLR was over $1.5 \mathrm{~kg} \mathrm{~m}^{-3} \mathrm{~d}^{-1}$, the removal efficiency of $\mathrm{BOD}_{5}$ decreased lower than $90 \%$ in R4 which was statistically different from the other operated with lower than $1.5 \mathrm{~kg} \mathrm{~m}^{-3} \mathrm{~d}^{-1}(\mathrm{R} 1-3)(\mathrm{p}<0.05)$. During the experimental period, the removal efficiencies of $\mathrm{BOD}_{5}$ were very stable under the condition of below $1.5 \mathrm{~kg} \mathrm{~m}^{-3} \mathrm{~d}^{-1}$ though $\mathrm{BOD}_{5}$ concentration in influent was highly fluctuated. Such a high endurance against the fluctuation of the influent concentration could be one of advantages on a biofilm reactor over suspended growth reactors (Rahimi et al., 2011).

As result of $\mathrm{NH}_{4}-\mathrm{N}$ removal efficiency, it was thought that the aeration rate of $0.12 \mathrm{~m}^{3} \mathrm{~h}^{-1}$ might provide sufficient oxygen for nitrification since $\mathrm{NH}_{4}-\mathrm{N}$ removal efficiency was over $90 \%$ except R4 (the highest NLR $0.58 \mathrm{~kg} \mathrm{~m}^{-3} \mathrm{~d}^{-1}$ ) (Table 2).

Seyfried et al. (2001) described that the external carbon sources were required to achieve sufficient denitrification when $\mathrm{C} / \mathrm{N}$ ratio was below 2.5 . In this regard, the influent of this study contained insufficient carbon sources and $\mathrm{C} / \mathrm{N}$ ratio was only 2.1 based on the $\mathrm{BOD}_{5}$ as a readily available carbon source (Table 2). The high T-N removal efficiency was presumably due to SND without the addition of carbon 
Table 2. The characteristics of influent and removal efficiencies

\begin{tabular}{|c|c|c|c|c|c|c|c|c|c|}
\hline \multirow{2}{*}{ Parameters } & \multirow{2}{*}{$\begin{array}{c}\text { Influent } \\
\text { concentration } \\
\left(\mathrm{mg} \mathrm{L}^{-1}\right)\end{array}$} & \multicolumn{4}{|c|}{ Effluent concentration $\left(\mathrm{mg} \mathrm{L}^{-1}\right)$} & \multicolumn{4}{|c|}{ Removal efficiency (\%) } \\
\hline & & $\mathrm{R} 1$ & $\mathrm{R} 2$ & $\mathrm{R} 3$ & $\mathrm{R} 4$ & $\mathrm{R} 1$ & $\mathrm{R} 2$ & $\mathrm{R} 3$ & $\mathrm{R} 4$ \\
\hline \multirow[t]{2}{*}{$\mathrm{BOD}_{5}$} & $2,175.3$ & $106.7^{\mathrm{b}}$ & $154.9^{\mathrm{b}}$ & $137.0^{\mathrm{b}}$ & $277.2^{\mathrm{a}}$ & 95.1 & 92.9 & 93.7 & 87.3 \\
\hline & $\pm 1,705.5$ & \pm 31.4 & \pm 36.8 & \pm 33.4 & \pm 160.6 & \pm 3.7 & \pm 4.1 & \pm 4.4 & \pm 16.2 \\
\hline \multirow{2}{*}{$\mathrm{COD}_{\mathrm{cr}}$} & $2,713.9$ & 786.2 & 803.1 & 913.2 & $1,299.6$ & 71.0 & 70.4 & 66.4 & 52.1 \\
\hline & $\pm 1,261.2$ & \pm 61.9 & \pm 40.3 & \pm 50.3 & \pm 198.7 & \pm 15.6 & \pm 10.4 & \pm 7.9 & \pm 9.8 \\
\hline \multirow[t]{2}{*}{$\mathrm{T}-\mathrm{N}$} & $1,010.8$ & $112.4^{\mathrm{b}}$ & $157.6^{\mathrm{b}}$ & $167.7^{\mathrm{b}}$ & $280.4^{\mathrm{a}}$ & 88.9 & 84.4 & 83.4 & 72.3 \\
\hline & \pm 446.6 & \pm 58.7 & \pm 78.2 & \pm 74.3 & \pm 188.4 & \pm 6.1 & \pm 10.2 & \pm 9.5 & \pm 23.0 \\
\hline \multirow[t]{2}{*}{$\mathrm{NH}_{4}-\mathrm{N}$} & 198.3 & 4.1 & 7.0 & 8.3 & 39.3 & 95.8 & 92.6 & 91.8 & 69.8 \\
\hline & \pm 77.6 & \pm 6.5 & \pm 10.4 & \pm 9.7 & \pm 29.9 & \pm 7.4 & \pm 12.2 & \pm 11.0 & \pm 22.1 \\
\hline \multirow[t]{2}{*}{$\mathrm{NO}_{\mathrm{X}}-\mathrm{N}$} & 2.5 & 3.2 & 9.0 & 10.9 & 5.3 & - & - & - & - \\
\hline & \pm 5.6 & \pm 5.5 & \pm 11.8 & \pm 16.9 & \pm 13.0 & & & & \\
\hline \multirow[t]{2}{*}{ T-P } & 153.6 & 54.9 & 66.1 & 74.0 & 95.7 & 64.2 & 57.0 & 51.8 & 37.7 \\
\hline & \pm 67.5 & \pm 30.7 & \pm 35.1 & \pm 48.8 & \pm 47.0 & \pm 20.8 & \pm 27.7 & \pm 23.5 & \pm 25.0 \\
\hline \multirow[t]{2}{*}{ O-P } & 52.3 & 21.5 & 21.2 & 22.6 & 28.7 & 58.9 & 59.5 & 56.8 & 45.1 \\
\hline & \pm 10.0 & \pm 8.1 & \pm 8.5 & \pm 9.5 & \pm 9.3 & \pm 18.9 & \pm 20.8 & \pm 20.1 & \pm 18.5 \\
\hline \multirow[t]{2}{*}{ TS } & $2,993.1$ & $1,465.7$ & $1,683.9$ & $1,663.3$ & $1,841.0$ & 49.9 & 42.4 & 43.1 & 37.1 \\
\hline & $\pm 1,123.6$ & \pm 707.0 & \pm 660.4 & \pm 500.8 & \pm 622.9 & \pm 15.6 & \pm 14.4 & \pm 14.3 & \pm 15.5 \\
\hline \multirow[t]{2}{*}{ TVS } & $1,497.3$ & 916.8 & 902.3 & 887.4 & 911.9 & 35.5 & 36.5 & 37.6 & 35.9 \\
\hline & \pm 691.9 & \pm 428.6 & \pm 422.4 & \pm 400.5 & \pm 478.4 & \pm 28.3 & \pm 26.7 & \pm 27.3 & \pm 30.2 \\
\hline \multirow[t]{2}{*}{ SS } & 707.7 & 77.6 & 92.0 & 108.1 & 162.3 & 91.0 & 89.3 & 87.4 & 81.1 \\
\hline & \pm 499.8 & \pm 74.1 & \pm 103.0 & \pm 130.9 & \pm 154.8 & \pm 9.8 & \pm 11.5 & \pm 15.0 & \pm 18.9 \\
\hline \multirow[t]{2}{*}{ VSS } & 72.8 & 45.6 & 45.8 & 45.3 & 55.9 & 55.9 & 55.7 & 56.2 & 46.9 \\
\hline & \pm 57.4 & \pm 44.4 & \pm 46.4 & \pm 54.5 & \pm 51.8 & \pm 28.9 & \pm 31.7 & \pm 29.1 & \pm 25.7 \\
\hline
\end{tabular}

$\mathrm{BOD}_{5}$, biochemical oxygen demand; $\mathrm{COD}_{\mathrm{cr}}$, chemical oxygen demand; T-N, total nitrogen; T-P, total phosphate; O-P, ortho phosphate; TS, total solids; TVS, total volatile solids; SS, suspended solids; VSS, volatile suspended solids.

${ }^{\mathrm{a}, \mathrm{b}}$ Different superscript in the row of $\mathrm{BOD}_{5}$ and T-N effluent concentration indicates statistical differences among R1 to R4.

sources. As seen in Table 2, NOx-N concentration was maintained at relatively low levels, whereby the high performance of nitrogen removal was achieved, which may support SND occurred in the biofilm reactor. In addition, DO level in all the biofilm reactor during the experimental period was $0.37 \pm 0.02 \mathrm{mg} \mathrm{DO} \mathrm{\textrm {L } ^ { - 1 }}$ which was the appropriate level of 0.2 to $0.5 \mathrm{mg} \mathrm{DO} \mathrm{L}^{-1}$ for SND (Moriyama et al., 1990).

The Figure 3 displays T-N concentrations in effluent and removal efficiencies according to the different NLR from
0.14 to $0.58 \mathrm{~kg} \mathrm{TN} \mathrm{m}^{-3} \mathrm{~d}^{-1}$. The T-N removal efficiency was relatively high over $83 \%$ except R4 (the highest NLR of $0.58 \mathrm{~kg} \mathrm{~m}^{-3} \mathrm{~d}^{-1}$ ) at which the effluent concentration of T-N was statistically different from the other conditions in NLR $\left(\mathrm{R} 1,2\right.$, and 3) $(\mathrm{p}<0.05)$ and NLR $0.45 \mathrm{~kg} \mathrm{TN} \mathrm{m}^{-3} \mathrm{~d}^{-1}$ was a threshold level to obtain higher nitrogen removal efficiency.

\section{Selection of air-diffuser position}

In order to determine if the nitrification and denitrification occurs in upper and lower zones of air-

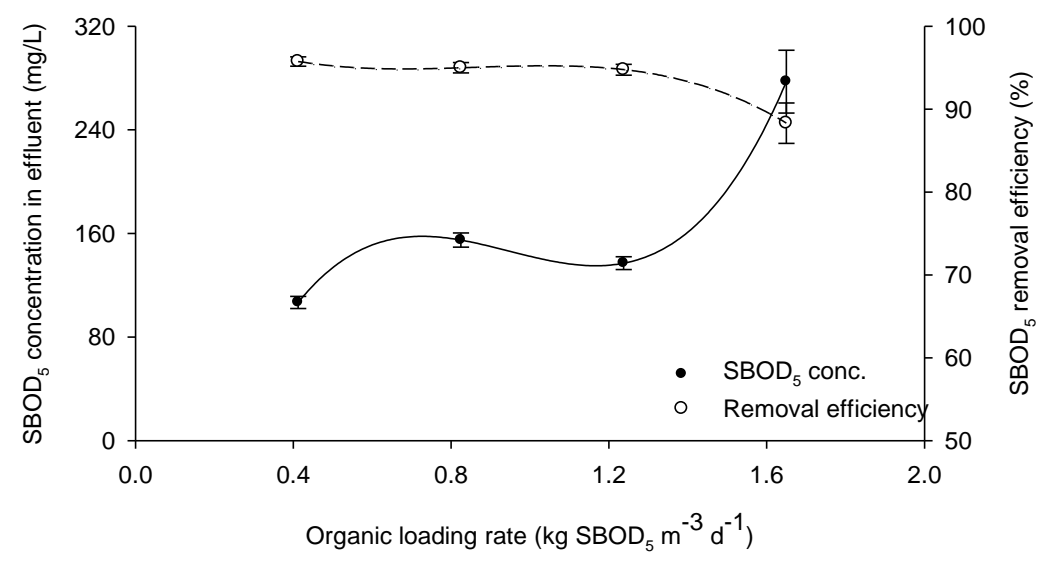

Figure 2. $\mathrm{BOD}_{5}$ concentration in the effluent and removal efficiencies according to organic loading rate. $\mathrm{BOD}_{5}$, biochemical oxygen demand. 


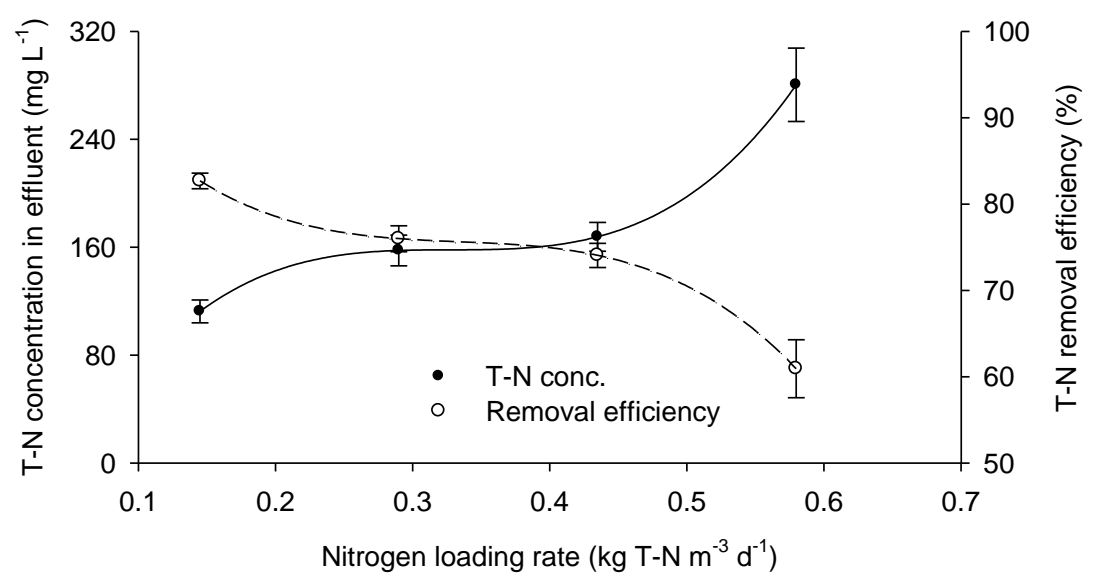

Figure 3. Total nitrogen concentration in effluent and removal efficiencies according to nitrogen loading rate.

diffuser corresponded with aerobic and anaerobic zones, respectively, nitrogen contents in liquid phase at the biofilm reactor were analyzed right after collecting liquid samples using the side ports as drawn in Figure 1.

With higher NLR of $0.58 \mathrm{~kg} \mathrm{~m}^{-3} \mathrm{~d}^{-1}$ (corresponding to $\mathrm{R} 4)$, difference of $\mathrm{NOx}-\mathrm{N}$ concentration at aerobic and anoxic zone was around $6.2 \mathrm{mg} \mathrm{NOx}-\mathrm{N} \mathrm{L}^{-1}$ which was much higher than the others of 0.6 to $0.8 \mathrm{mg} \mathrm{NOx}-\mathrm{N} \mathrm{L}^{-1}$ in R1, 2, and 3 (Figure 4). Since the characteristics of the influent was all the same for each reactor but the difference was only the flow rate of the influent, the HRT and NLR were proportionally governed by the flow rate. It has been known that SND is absolutely influenced by DO concentration and the thickness of biofilm but NLR can also be one of sub-factors for SND since the active nitrification at the surface of biofilm consumes DO dependent on NLR and further the limit of oxygen in the biofilm induces to form anoxic condition for the denitrification by oxygen concentration gradient, which results in the overall efficiency of nitrogen removal. Thus, nitrification and denitrification simultaneously occurred in $\mathrm{R} 1,2$, and 3 except R4 regardless of aerobic and anoxic condition via SND.

Hence, the position of air-diffuser was changed to the bottom of the reactor (presenting "bottom") and the performance of nitrogen removal was compared to the reactor in which air-diffuser was placed at the one third from the bottom of the reactor (presenting "middle") under the same NLR condition of $0.1 \mathrm{~kg} \mathrm{~m}^{-3} \mathrm{~d}^{-1}$ with the constant aeration rate of $0.12 \mathrm{~m}^{3} \mathrm{~h}^{-1}$.

There were no big differences in $\mathrm{NH}_{4}-\mathrm{N}$ removal efficiency according to the changes of air-diffuser position as seen in Figure 5. However, the better performance of denitrification, based on the result of NOx-N concentration, was found at the reactor with middle over bottom airdiffuser, whereby T-N concentration operated with middle air-diffuser showed the lower value than that with bottom air-diffuser. Though SND occurred in all reactors with both positions of air diffuser, the one third position of air-diffuser might help the performance of denitrification below the air-

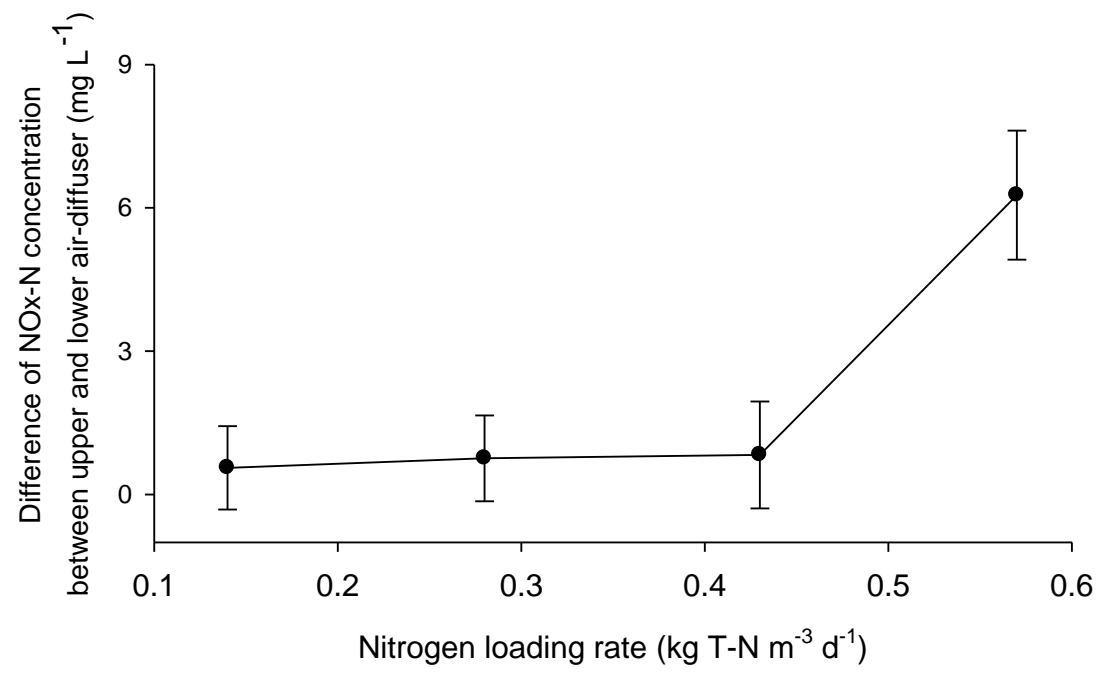

Figure 4. Difference of $\mathrm{NO}_{\mathrm{x}}-\mathrm{N}$ concentration between above and below air-diffuser in each reactor. 


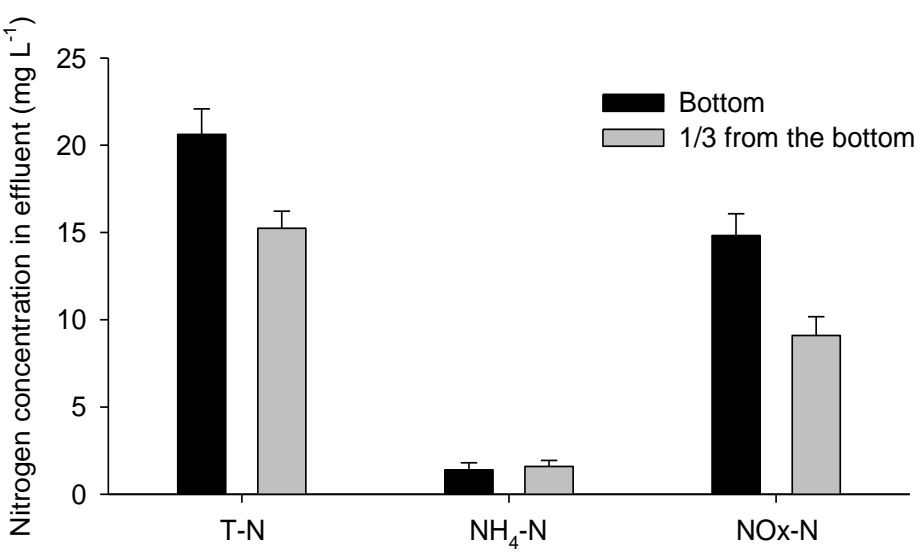

Figure 5. The concentration of nitrogen contents derived from two different positions of air-diffuser.

diffuser. In other words, the residual NOx-N from the upper zone was further reduced in the lower zone, which may be caused by aeration rate. Thus, the one-third from the bottom of the reactor was selected as a better position of airdiffuser to obtain higher nitrogen removal efficiency.

\section{Evaluation of aeration rate}

Under the same conditions of NLR $0.21 \mathrm{~kg} \mathrm{~m}^{-3} \mathrm{~d}^{-1}$ and the position of air-diffuser at one third from the bottom of the reactor, aeration rates of $0.06,0.12$, and $0.24 \mathrm{~m}^{3} \mathrm{~h}^{-1}$ were given to three reactors separately.

Once air were supplied, the nitrification was relatively well achieved on $\mathrm{NH}_{4}-\mathrm{N}$ removal efficiency of $93.9 \%$, $98.3 \%$, and $98.9 \%$ in each reactor with aeration rates of $0.06,0.12$, and $0.24 \mathrm{~m}^{3} \mathrm{~h}^{-1}$, respectively. With aeration rate of 0.12 and $0.24 \mathrm{~m}^{3} \mathrm{~h}^{-1}, \mathrm{NH}_{4}-\mathrm{N}$ in influent was almost completely oxidized. However, aeration rate of $0.06 \mathrm{~m}^{3} \mathrm{~h}^{-1}$ might be insufficient to achieve the complete oxidation of $\mathrm{NH}_{4}-\mathrm{N}$ when compared to the other higher aeration rate, which resulted in the highest T-N amount remained in the effluent (Figure 6). During this test, DO level with aeration

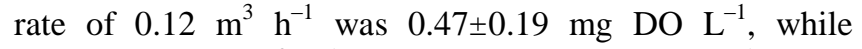
aeration of $0.24 \mathrm{~m}^{3} \mathrm{~h}^{-1}$ led to $2.14 \pm 0.95 \mathrm{mg}$ DO $\mathrm{L}^{-1}$. Thus, the SND might be inhibited with higher aeration of $0.24 \mathrm{~m}^{3}$ $\mathrm{h}^{-1}$ since oxygen gradient was not reached zero at the bottom layer of biofilm. The high efficiency of nitrogen removal with the high DO concentration was achieved with the conventional nitrification and denitrification under the separated zones, formally aerobic and anoxic zones. In addition, since SND can be achieved with the partial oxidation of ammonium to nitrite (Surmacz-Gòrska et al., 1997; Yoo et al., 1999), then reduced to $\mathrm{N}_{2}$ gas, the efficiency of nitrogen removal with SND might be better over the conventional nitrification and denitrification through formally aerobic and anoxic zones.

Accordingly, when compared to an aeration rate of 0.24 $\mathrm{m}^{3} \mathrm{~h}^{-1}$, the slightly better performance of nitrogen removal was obtained with an aeration rate of $0.12 \mathrm{~m}^{3} \mathrm{~h}^{-1}$ which was determined as the optimal aeration rate and resulted in DO range of 0.2 to $0.5 \mathrm{mg} \mathrm{DO} \mathrm{L^{-1 }}$ for an appropriate SND condition $\left(0.47 \pm 0.19 \mathrm{mg} \mathrm{DO} \mathrm{L}^{-1}\right.$ in this study).

In the present study, nitrogen removal from MCW was investigated using the biofilm filtration reactor of which the operational conditions (NLR, the position of air-diffuser, and an aeration rate) were optimized without the addition of external carbon sources. Although the external carbon sources are generally required for the denitrification since $\mathrm{MCW}$ contains a relatively low $\mathrm{C} / \mathrm{N}$ ratio (2.1 in this study),

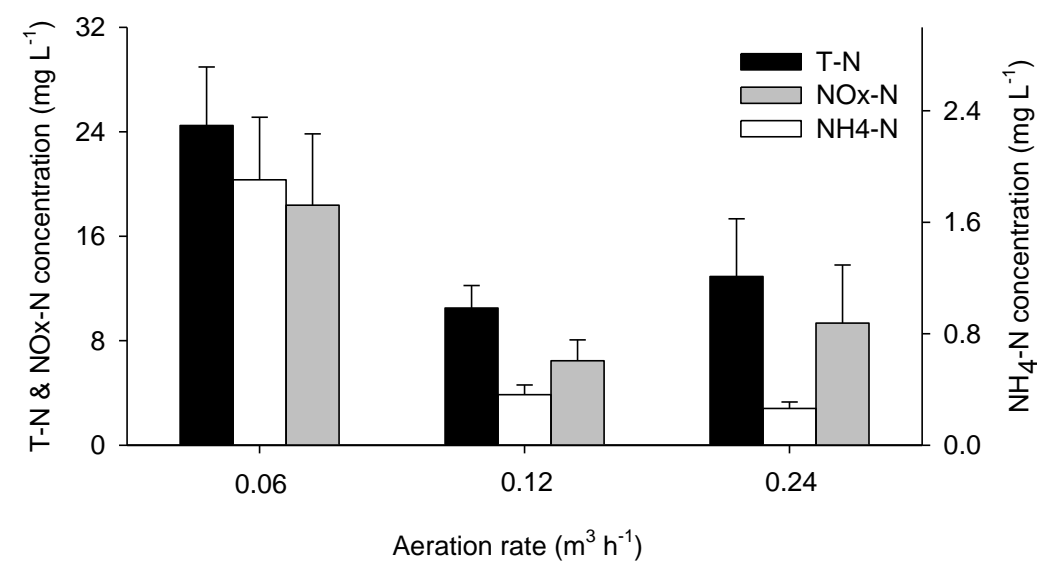

Figure 6. Nitrogen concentration according to aeration rate. 
nitrogen removal was successfully achieved via SND in biofilm filtration reactor packed with sand as a bedding material. Biofilm formed by attached growth microorganisms has an oxygen gradient with the thickness of biofilm. Thus, the inner zone of biofilm has an oxygen zero condition, which facilitates to perform the denitrification.

As result of the evaluation of the operational parameters, the higher nitrogen removal was obtained when NLR was $0.45 \mathrm{~kg} \mathrm{~m}^{-3} \mathrm{~d}^{-1}$ and aeration rate of $0.12 \mathrm{~m}^{3} \mathrm{~h}^{-1}$ was selected to maintain the optimal DO level for SND. The active nitrogen removal with higher aeration rate of $0.24 \mathrm{~m}^{3} \mathrm{~h}^{-1}$ was presumably achieved by the conventional anoxic condition below air-diffuser. There was no big difference in the performance of nitrogen removal due to the air-diffuser position between the bottom and the one third from the bottom of the reactor but one third position could have a benefit to failure of SND. In order to investigate SND with the oxygen gradient according to the thickness of biofilm on a bedding material, the study of nitrite to nitrate ratio will be required in the future.

\section{ACKNOWLEDGMENTS}

We are thankful for the funding in the project of (PJ009392) by Rural Development Administration, Korea.

\section{REFERENCES}

American Public Health Association (APHA). 1995. Standard Methods for the Examination of Water and Wastewater, 10th edition, APHA, Washington, DC, USA.

Gupta, S. K., S. M. Raja, and A. B. Gupta. 1994. Simultaneous nitrification-denitrification in a rotating biological contactor. Environ. Technol. 15:145-153.

Halling, S. B. and H. Hjuler. 1992. Simultaneous nitrification and denitrification with an upflow fixed bed reactor applying clinoptilolite as media. Water Treat. 7:77-88.

Irvine, R. L., D. V. S. Murthy, J. L. Arora, J. L. Copeman, and J. A. Heidman. 1987. Analysis of full-scale SBR operation at Grundy Centre. Iowa. J. Water Pollut. Control Fed. 59:132-138.
Masuda, S., Y. Watanabe, and M. Ishiguro. 1991. Biofilm properties and simultaneous nitrification and denitrification in aerobic rotating biological contactors. Water Sci. Technol. 23: 1355-1363.

Moriyama, K., K. Sato, Y. Harada, K. Washiyama, and K. Okamoto. 1990. Simultaneous biological removal of nitrogen and phosphorus using oxic-anaerobic-oxic process. Water Sci. Technol. 22(7/8):61-66.

Münch, E. V., P. Lant, and J. Keller. 1996. Simultaneous nitrification and denitrification in bench-scale sequencing batch reactors. Water Res. 30:277-284.

Rahimi, Y., A. Torabian, N. Mehrdadi, and B. Shahmoradi. 2011. Simultaneous nitrification-denitrification and phosphorus removal in a fixed bed sequencing batch reactor. J. Hazard. Mater. 185:852-857.

Safferman, S. 2008. Milking facility wash water: Facts and figures. Michigan Dairy Rev. 13:1-2.

Sen, P. and S. K. Dentel. 1998. Simultaneous nitrificationdenitrification in a fluidized bed reactor. Water Sci. Technol. $38: 247-254$.

Seyfried, C. F., A. Hippen, C.. Hlmer, S. Junst, and K.-H. Rosenwinkel. 2001. One-stage deammonification: nitrogen elimination at low costs. Water Sci. Technol. 1:71-80.

Surmacz-Gòrska, J., A. Cichon, and K. Miksch. 1997. Nitrogen removal from wastewater with high ammonia nitrogen concentration via shorter nitrification and denitrification. Water Sci. Technol. 36:73-78.

Tchobanoglous, G., F. Burton, and H. Stensel. 2003. Wastewater Engineering Treatment and Reuse (4th Edn.). Metcalf \& Eddy Inc., McGraw Hill, New York, USA.

Turk, O. and D. S. Mavinic. 1986. Preliminary assessment of a shortcut in nitrogen removal from wastewater. Can. J. Civil Eng. 13:600-605.

Turk, O. and D. Mavinic. 1989. Maintaining nitrite build-up in a system acclimated to free ammonia. Water Res. 23:1383-1388.

Yoo, H., K. -H. Ahn, H. -J. Lee, K. -H. Lee, Y. -J. Kwak, and K. G. Song. 1999. Nitrogen removal from synthetic wastewater by simultaneous nitrification and denitrification (SND) via nitrite in an intermittently-aerated reactor. Water Res. 33:145-154.

Zeng, R. J., R. Lemaire, Z. Yuan, and J. Keller. 2003. Simultaneous nitrification, denitrification, and phosphorus removal in a lab-scale sequencing batch reactor. Biotechnol. Bioeng. 84:170-178. 